\title{
Structural modifications leading to changes in supramolecular aggregation of thiazolo[3, 2-a]pyrimidines: Insights into their conformational features
}

\author{
H NAGARAJAIAH and NOOR SHAHINA BEGUM* \\ Department of Studies in Chemistry, Bangalore University, Bangalore 560 001, India \\ e-mail:noorsb05@gmail.com;noorsb@rediffmail.com
}

MS received 29 January 2014; revised 16 April 2014; accepted 14 May 2014

\begin{abstract}
The compounds, 7-methyl-3,5-diphenyl-5H-thiazolo[3,2-a]pyrimidine-6-carboxylic acid ethyl ester (1), 3-amino-2-cyano-7-methyl-5-phenyl-5H-thiazolo[3,2-a]pyrimidine-6-carboxylic acid methyl ester (2), 2-dimethylaminomethylene-7-methyl-3-oxo-5-phenyl-2,3-dihydro-5H-thiazolo[3,2-a]pyrimidine6-carboxylic acid ethyl ester (3), 2-(3-cyano-benzylidene)-5-(4-hydroxy-phenyl)-7-methyl-3-oxo-2,3dihydro-5H-thiazolo[3,2-a]pyrimidine-6-carboxylic acid methyl ester; with $N, N$-dimethyl-formamide (4) and 3-ethoxycarbonylmethyl-5-(4-hydroxy-3-methoxy-phenyl)-7-methyl-5H-thiazolo[3,2-a]pyrimidine-6carboxylic acid methyl ester (5) have been synthesized and their structures evaluated crystallographically. Compound 1 crystallizes in the space group $P^{\overline{1}}$ with $\mathrm{Z}=8$, with four molecules in the asymmetric unit. Compound 2 also crystallizes in the space group $P \overline{1}$ with $\mathrm{Z}=4$ wherein asymmetric unit accommodates two molecules. Compound 3 belongs to $P 2_{1} / \mathrm{c}$ with $\mathrm{Z}=4$, compound 4 crystallizes in $P$ bc $2_{1}$ with $\mathrm{Z}=4$ and compound 5 belongs to $P^{\overline{1}}$ with $\mathrm{Z}=2$. In all the above compounds, the aryl ring positioned at $\mathrm{C} 5$ of thiazolopyrimidine ring is almost perpendicular. In the case of compounds with substituted phenyl ring, aryl group-up conformation predominates. However, for compounds with unsubstituted phenyl ring, aryl group-down conformation is adopted. By varying the substituents at positions C2, C3, C6 and on the aryl at C5 in the main molecular scaffold of (1-5), we have observed significant differences in the intermolecular interaction patterns. The packing features of the compounds are controlled by C-H. .O, C-H. . N, N-H. .N O-H. . N, C-H. . $\pi$ and $\pi \ldots \pi$ weak interactions.
\end{abstract}

Keywords. Thiazolo[3,2-a]pyrimidines; conformational analysis; C-H. ..O, C-H. . .N, N-H. .N, O-H. ..N, $\mathrm{C}-\mathrm{H} . . . \pi$ and $\pi \ldots \pi$ weak interactions.

\section{Introduction}

Thiazolo[3,2-a]pyrimidine derivatives are potential bioactive molecules. These have been of interest due to their anti-microbial, ${ }^{1-5}$ anti-inflammatory ${ }^{6}$ and anti-hypertensive activities. Thiazolo[3,2-a]pyrimidine compounds have interesting biological potentialities, particularly as inotropic agents and novel therapeutically active entities for severe neurodegenerative diseases. ${ }^{7}$ In addition, thiazolo[3,2- $a$ ]pyrimidine derivatives have shown significant anti-malarial and HIVRT inhibitory activities. Recently, a new series of thiazolo[3,2- $a$ ]pyrimidines have been identified to exhibit anti-inflammatory and anti-nociceptive activities. ${ }^{8}$

In view of the tremendous application of this class of compounds, we have substituted different substituents on the thiazolopyrimidine ring at various positions. One of the objectives of these structure determinations was to investigate how the introduction of different

\footnotetext{
*For correspondence
}

substituents influences the supramolecular aggregations. We have recently reported a number of crystal structures of thiazolo[3,2-a]pyrimidine derivatives with various substituents. ${ }^{9 a-c}$ In the present work we have investigated the role of functional groups on molecular geometry, conformation and generation of supramolecular assemblies in the solid state. In this regard, the understanding of molecular recognition processes enables a better understanding of the physical and chemical properties of the solid. It is a cooperative interplay amongst both strong hydrogen bonds and weak intermolecular interactions which dictate overall packing in the crystal lattice.

\section{Experimental}

\subsection{Synthesis}

Syntheses of compounds $\mathbf{1 - 5}$ is given in scheme 1 . The compound $\mathbf{1}$ was synthesized according to the reported procedure ${ }^{7}$ by treating 6-methyl-4-phenyl- 


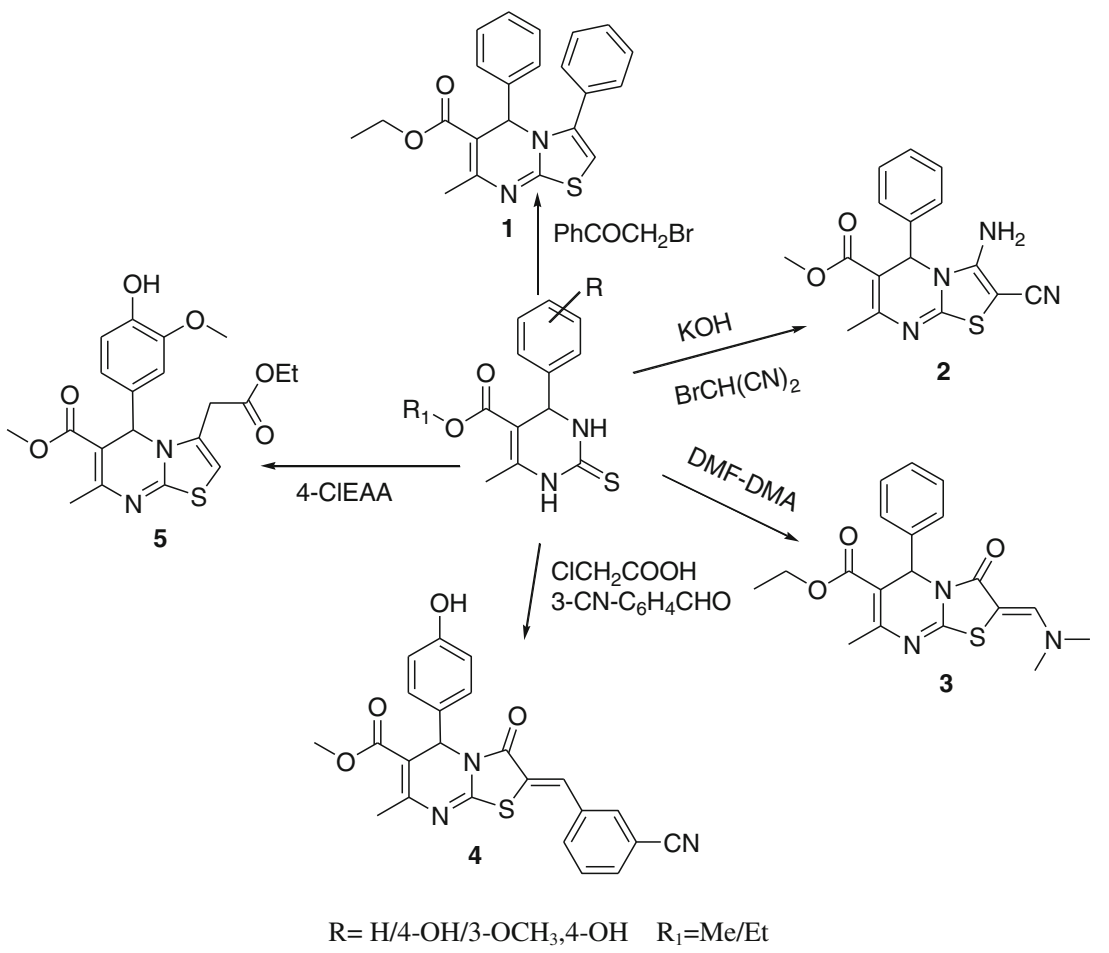

Scheme 1. Synthesis of various thiazolopyrimidines.

2-thioxo-1,2,3,4-tetrahydro-pyrimidine-5-carboxylic acid ethyl ester with phenacyl-bromide in equimolar quantities. Compound $\mathbf{2}$ was prepared by reacting 6-methyl-4-phenyl-2-thioxo-1,2,3,4-tetrahydropyrimidine-5-carboxylic acid methyl ester with monobromo malanonitrile using strong base under warm condition. ${ }^{10}$ Compound $\mathbf{3}$ was obtained by refluxing 6-methyl-4-phenyl-2-thioxo-1,2,3,4-tetrahydropyrimidine-5-carboxylic acid ethyl ester with dimethylformamide-dimethylacetal. Compound $\mathbf{4}$ was synthesized according to the procedure described ${ }^{9 a, 11}$ by treating 4-(4-hydroxy-phenyl)-6-methyl-2-thioxo1,2,3,4-tetrahydro-pyrimidine-5-carboxylic acid methyl ester with chloro-acetic acid and 3-cyano benzaldehyde in presence of sodium acetate. Synthesis of compound 5 was followed by the method reported earlier. ${ }^{3}$

\section{$2.2 X$-ray diffraction analysis}

Single crystals of compounds $\mathbf{1 - 5}$ were obtained by slow evaporation from a solution using ethylacetate, DMF and ethanol solvents for compounds 1-2, 3-4 and 5 respectively

A good single crystal in each case was mounted along its largest dimension and used for data collection. The intensity data were collected on a Bruker Smart CCD Area Detector System using MoK $\alpha(0.71073 \AA)$ radiation in $\omega-\Phi$ scan mode. The data were reduced using SAINT-Plus. ${ }^{12}$ The structure in each case was solved by Direct Methods and refined on $\mathrm{F}^{2}$ using SHELX-97 ${ }^{13}$ package. All the non-hydrogen atoms were refined anisotropically. As the hydrogens were not readily revealed from difference Fourier maps, they were included in the ideal positions with fixed isotropic $U$ values, and they were riding with their respective non-hydrogen atoms. The difference Fourier map, after the refinement, was essentially featureless in all cases. The mean plane calculations were done using the program PARST. ${ }^{14}$ Diagrams and publication material were generated using ORTEP- $3,{ }^{15}$ PLATON, ${ }^{16}$ CAMERON $^{17}$ and DIAMOND. ${ }^{18}$

\section{Results and Discussion}

\subsection{Crystallography}

Summary of crystallographic data and other structure refinement parameters of the compounds $\mathbf{1 - 5}$ are given in table 1. Table 2 gives hydrogen bond parameters in compounds 1-5. Table 3 gives the conformational parameters. The ORTEP view of the molecules 1-5 with atomic labeling (thermal ellipsoids drawn at 50\% probability) is shown in figure 1. Figures 2 and 3 show $\mathrm{C}-\mathrm{H}$...O and C-H...N intermolecular interactions in compound 1. Packing of molecules for compounds 2-5 are shown in figures 4-7 respectively.

Compounds 1, 2 and 5 crystallize in the triclinic crystal system with four, two and one molecule in the 
Table 1. Crystal data and refinement parameters for $\mathbf{1 5 .}$

\begin{tabular}{|c|c|c|c|}
\hline & 1 & 2 & 3 \\
\hline Formula & $\mathrm{C}_{22} \mathrm{H}_{20} \mathrm{~N}_{2} \mathrm{O}_{2} \mathrm{~S}$ & $\mathrm{C}_{16} \mathrm{H}_{14} \mathrm{~N}_{4} \mathrm{O}_{2} \mathrm{~S}$ & $\mathrm{C}_{19} \mathrm{H}_{21} \mathrm{~N}_{3} \mathrm{O}_{3} \mathrm{~S}$ \\
\hline $\mathrm{M}$ & 376.47 & 326.37 & 371.45 \\
\hline$T / \mathrm{K}$ & $100(2)$ & $100(2)$ & $100(2)$ \\
\hline Crystal size $/ \mathrm{mm}^{3}$ & $0.18 \times 0.16 \times 0.16$ & $0.18 \times 0.16 \times 0.16$ & $0.18 \times 0.16 \times 0.16$ \\
\hline Crystal system & Triclinic & Triclinic & Monoclinic \\
\hline Space group & $P \overline{1}$ & $P \overline{1}$ & $P 2_{1} / \mathrm{c}$ \\
\hline$a / \AA$ & $10.2794(5)$ & $9.7071(13)$ & $8.6855(6)$ \\
\hline$b / \AA$ & $19.4444(9)$ & $13.7486(19)$ & $23.4318(16)$ \\
\hline$c / \AA$ & $20.9903(11)$ & $13.8865(19)$ & $8.9230(6)$ \\
\hline$\alpha /\left(^{\circ}\right)$ & $101.731(3)$ & $118.761(2)$ & \\
\hline$\beta /\left(^{\circ}\right)$ & $103.305(3)$ & $91.352(2)$ & $104.665(1)$ \\
\hline$\gamma /\left(^{\circ}\right)$ & $90.032(4)$ & $100.936(2)$ & 90 \\
\hline$V / \AA^{3}$ & 3992.6(3) & $1580.9(4)$ & $1756.8(2)$ \\
\hline $\mathrm{Z}, d_{\text {calcd }} /\left(\mathrm{g} \mathrm{cm}^{-3}\right)$ & $8,1.253$ & $4,1.371$ & $4,1.404$ \\
\hline$\mu / \mathrm{mm}^{-1}$ & 0.18 & 0.22 & 0.21 \\
\hline$F(000)$ & 1354 & 680 & 784 \\
\hline$\theta$ range $/\left(^{\circ}\right)$ & $1.32-27.00$ & $1.69-27.00$ & $1.74-25.00$ \\
\hline Index ranges & $-13 \leq \mathrm{h} \leq 12$ & $-12 \leq \mathrm{h} \leq 12$ & $10 \leq \mathrm{h} \leq 10$ \\
\hline & $-24 \leq \mathrm{k} \leq 24$ & $-17 \leq \mathrm{k} \leq 15$ & $27 \leq \mathrm{k} \leq 18$ \\
\hline & $-26 \leq 1 \leq 26$ & $17 \leq \overline{1} \leq \overline{16}$ & $-1 \leq 1 \leq 1$ \\
\hline Reflections collected & 67809 & 9727 & 9041 \\
\hline Independent & 17367 & 6712 & 3085 \\
\hline reflections & {$\left[\mathrm{R}_{\mathrm{int}}=0.076\right]$} & {$\left[\mathrm{R}_{\mathrm{int}}=0.0333\right]$} & {$\left[\mathrm{R}_{\mathrm{int}}=0.0219\right]$} \\
\hline Completeness & $99.7 \%$ & $971 \%$ & $99.6 \%$ \\
\hline Data/restraints/parameters & $17367 / 0 / 982$ & $6712 / 0 / 419$ & $3085 / 0 / 239$ \\
\hline Goodness-of-fit on $F^{2}$ & 1.118 & 0.985 & 0.998 \\
\hline$R_{1}, w R_{2}[I>2 \sigma(I)]$ & $0.086,0.2160$ & $0.081,0.2164$ & $0.039,0.1104$ \\
\hline$R_{1}, w R_{2}($ all data $)$ & $0.1960,0.2431$ & $0.1294,0.2947$ & $0.0427,0.1154$ \\
\hline \multirow[t]{2}{*}{ Largest diff. peak, hole/(e $\left.\mathrm{A}^{-3}\right)$} & $0.853,-0.383$ & $1.079,-0.725$ & $0.400,-0.299$ \\
\hline & 4 & \multicolumn{2}{|l|}{5} \\
\hline Formula & $\mathrm{C}_{26} \mathrm{H}_{24} \mathrm{~N}_{4} \mathrm{O}_{5} \mathrm{~S}$ & \multicolumn{2}{|l|}{$\mathrm{C}_{20} \mathrm{H}_{22} \mathrm{~N}_{2} \mathrm{O}_{6} \mathrm{~S}$} \\
\hline $\mathrm{M}$ & 504.55 & \multicolumn{2}{|l|}{418.46} \\
\hline$T / \mathrm{K}$ & $100(2)$ & \multicolumn{2}{|l|}{$100(2)$} \\
\hline Crystal size $/ \mathrm{mm}^{3}$ & $0.18 \times 0.16 \times 0.16$ & \multicolumn{2}{|l|}{$0.18 \times 0.16 \times 0.16$} \\
\hline Crystal system & Orthorhombic & \multicolumn{2}{|l|}{ Triclinic } \\
\hline Space group & $P$ ca2 1 & \multicolumn{2}{|l|}{$P_{\overline{1}}^{\overline{1}}$} \\
\hline$a / \AA$ & 12.298 & \multicolumn{2}{|l|}{$7.0811(11)$} \\
\hline$b / \AA$ & 13.680 & \multicolumn{2}{|l|}{$8.2731(13)$} \\
\hline$c / \AA$ & 14.540 & \\
\hline$\alpha /\left(^{\circ}\right)$ & 90 & \multicolumn{2}{|l|}{$80.942(2)$} \\
\hline$\beta /\left(^{\circ}\right)$ & 90 & \multicolumn{2}{|l|}{$81.340(2)$} \\
\hline$\gamma /\left(^{\circ}\right)$ & 90 & \multicolumn{2}{|l|}{$83.065(3)$} \\
\hline$V / \AA^{3}$ & 2446.2 & \multicolumn{2}{|l|}{$981.3(3)$} \\
\hline $\mathrm{Z}, d_{\text {calcd }} /\left(\mathrm{g} \mathrm{cm}^{-3}\right)$ & $4,1.370$ & \multicolumn{2}{|l|}{$2,1.416$} \\
\hline$\mu / \mathrm{mm}^{-1}$ & 0.178 & \multicolumn{2}{|l|}{0.206} \\
\hline$F(000)$ & 1056 & 440 & \\
\hline$\theta$ range $/\left(^{\circ}\right)$ & $2.23-25.00$ & $2.41-27.00$ & \\
\hline Index ranges & $-14 \leq \mathrm{h} \leq 14$ & $-9 \leq h \leq 8$ & \\
\hline & $-13 \leq \mathrm{k} \leq 16$ & $-9 \overline{\mathrm{k}} \leq 1$ & \\
\hline & $-15 \leq 1 \leq 17$ & $-21 \leq 1 \leq 18$ & \\
\hline Reflections collected & 12107 & 5793 & \\
\hline Independent & 4152 & 4103 & \\
\hline reflections & {$\left[\mathrm{R}_{\mathrm{int}}=0.0638\right]$} & {$\left[\mathrm{R}_{\mathrm{int}}=0.0219\right]$} & \\
\hline Completeness & $100.0 \%$ & $962 \%$ & \\
\hline Data/restraints/parameters & $4152 / 1 / 333$ & $4103 / 0 / 279$ & \\
\hline Goodness-of-fit on $F^{2}$ & 1024 & 1.458 & \\
\hline$R_{1}, w R_{2}[I>2 \sigma(I)]$ & $0.0653,0.1496$ & $0.074,0.2062$ & \\
\hline$R_{1}, w R_{2}($ all data $)$ & $0.0969,0.1702$ & $0.1027,0.2838$ & \\
\hline Largest diff. peak, hole/(e $\left.\mathrm{A}^{-3}\right)$ & $0.357,-0.238$ & $0.788,-0.947$ & \\
\hline
\end{tabular}


Table 2. Non-bonded interactions and possible hydrogen bonds $\left(\AA \AA^{\circ}\right)$ for compounds 1-5 (D-donor; A-acceptor; Hhydrogen).

\begin{tabular}{lcccc}
\hline $\mathbf{D}-\mathbf{H} \cdots \mathbf{A}$ & $\mathbf{D}-\mathbf{H}$ & $\mathbf{H} \cdots \mathbf{A}$ & $\mathbf{D} \cdots \mathbf{A}$ & $\mathbf{D}-\mathbf{H} \cdots \mathbf{A}$ \\
\hline Compound 1 & & & & \\
$\mathrm{C} 2 \mathrm{c}-\mathrm{H} 2 \mathrm{c} \ldots \mathrm{O} 2 \mathrm{c}^{\mathrm{i}}$ & 0.930 & 2.330 & $3.223(6)$ & 161 \\
$\mathrm{C} 2 \mathrm{~d}-\mathrm{H} 2 \mathrm{~d} \ldots \mathrm{O} 2 \mathrm{~d}^{\mathrm{ii}}$ & 0.930 & 2.356 & $3.241(6)$ & 159 \\
$\mathrm{C} 18 \mathrm{c}-\mathrm{C} 18 \mathrm{c} \ldots \mathrm{O} 2 \mathrm{c}^{\mathrm{iii}}$ & 0.930 & 2.455 & $3.384(5)$ & 177 \\
$\mathrm{C} 18 \mathrm{~d}-\mathrm{H} 18 \mathrm{~d} . . \mathrm{O} 2 \mathrm{~d}^{\mathrm{iv}}$ & 0.930 & 2.448 & $3.377(4)$ & 176 \\
$\mathrm{C} 8 \mathrm{c}-\mathrm{H} 8 \mathrm{c} \ldots \mathrm{Cg} 1^{\mathrm{v}}$ & 0.970 & 2.951 & $3.728(6)$ & 146 \\
$\mathrm{C} 8 \mathrm{~d}-\mathrm{H} 8 \mathrm{~d} \ldots \mathrm{Cg} 2^{\text {vi }}$ & 0.970 & 2.932 & $3.774(5)$ & 147 \\
C13a-H13a..Cg3 & 0.930 & 3.086 & $3.896(2)$ & vii
\end{tabular}

Symmetry code: ( i) $x+1,+y,+z$ (ii) $x-1,+y,+z$ (iii) $-x+1,-y+1,-z$ (iv) $-x+1,-y+2,-z$

(v) $-x,+y-1 / 2,+z$ (vi) $1-x, 2-y,-z$ (vii) $1-x, 1-y,-0.5+z$

\section{Compound 2}

$\begin{array}{lllll}\mathrm{N} 3 \mathrm{a}-\mathrm{H} 3 \mathrm{a} 1 \ldots \mathrm{N} 2 \mathrm{~b}^{\mathrm{i}} & 0.860 & 2.086 & 2.809(7) & 141 \\ \mathrm{~N} 3 \mathrm{~b}-\mathrm{H} 3 \mathrm{~b} 1 \ldots \mathrm{N} 2 \mathrm{a}^{\mathrm{ii}} & 0.860 & 2.051 & 2.839(6) & 152 \\ \mathrm{~N} 3 \mathrm{~b}-\mathrm{H} 3 \mathrm{~b} 2 \ldots \mathrm{N} 4 \mathrm{a}^{\mathrm{iii}} & 0.930 & 2.303 & 3.035(7) & 143 \\ \mathrm{C} 13 \mathrm{a}-\mathrm{H} 13 \mathrm{a} . . . \mathrm{O} 1 b^{\text {iv }} & 0.930 & 2.666 & 3.457(7) & 143\end{array}$

Symmetry code: ( i) $-\mathrm{x}+1,-\mathrm{y}+2,-\mathrm{z}-1$ (ii) $-\mathrm{x}+1,-\mathrm{y}+2,-\mathrm{z}$ (iii) $\mathrm{x}+1,+\mathrm{y},+\mathrm{z}$ (iv) $\mathrm{x}-1,+\mathrm{y}+1,+\mathrm{z}+1$

\section{Compound 3}

$\mathrm{C} 17-\mathrm{H} 17 \ldots \mathrm{O} 1^{\mathrm{i}}$

C18-H18a...O1 ${ }^{\mathrm{i}}$

$\mathrm{C} 14-\mathrm{H} 14 \ldots \mathrm{O} 2^{\mathrm{ii}}$

\section{Compound 4}

$\mathrm{C} 4-\mathrm{H} 4 \mathrm{a} . . . \mathrm{O} 5^{\mathrm{i}}$

$\mathrm{C} 13-\mathrm{H} 13 \ldots \mathrm{N} 3^{\mathrm{ii}}$

$\mathrm{C} 22-\mathrm{H} 22 \ldots \mathrm{O} 2^{\mathrm{iii}}$

C16-H16. . .O2 $2^{\text {iii }}$

$\mathrm{C} 18-\mathrm{H} 18 \ldots 1^{\text {iv }}$

$\mathrm{C} 20-\mathrm{H} 20 \ldots \mathrm{N} 2^{\mathrm{v}}$

C25-H25C...CgVii

$\begin{array}{llll}0.930 & 2.319 & 3.226(2) & 165 \\ 0.960 & 2.475 & 3.380(2) & 157 \\ 0.960 & 2.651 & 3.453(2) & 141\end{array}$

Symmetry code: ( i) $-\mathrm{x},-\mathrm{y}+1,-\mathrm{z}+2$ (ii) $\mathrm{x}+1,+\mathrm{y},+\mathrm{z}$

$\begin{array}{llll}0.960 & 2.595 & 3.550(5) & 173 \\ 0.930 & 2.498 & 3.223(3) & 134 \\ 0.930 & 2.219 & 3.045(5) & 147 \\ 0.930 & 2.359 & 3.198(5) & 150 \\ 0.930 & 2.309 & 3.091(6) & 141 \\ 0.930 & 2.411 & 3.168(5) & 138 \\ 0.960 & 3.020 & 3.957(3) & 143\end{array}$

Symmetry code: (i) $-x-1 / 2,+y,+z+1 / 2$, (ii) $-x,-y+2,+z+1 / 2$, (iii) $-x,-y+2,+z-1 / 2$, (iv) $\mathrm{x}+1 / 2,-\mathrm{y}+2,+\mathrm{z},(\mathrm{v})-\mathrm{x}+1,-\mathrm{y}+2,+\mathrm{z}-1 / 2$, (vi) $-1 / 2-\mathrm{x}, \mathrm{y}, 1 / 2+\mathrm{z}$

Compound 5

O6-H6. . .N2 ${ }^{\mathrm{i}}$

C16-H16C...O3 ${ }^{\mathrm{ii}}$

$\mathrm{C} 12-\mathrm{H} 12 \ldots \mathrm{Cg}_{1}^{\mathrm{iii}}$

$0.820(3)$

$0.960(3)$

$0.960(2)$

$2.081(3)$

$2.521(2)$

$3.120(3)$

$2.882(4)$

$3.401(3)$

$3.977(5)$

165

152

153

Symmetry code: ( i) $-\mathrm{x}+1,-\mathrm{y}+1,-\mathrm{z}+1$ (ii) $-\mathrm{x},-\mathrm{y}+1,-\mathrm{z}$ (iii) $1-\mathrm{x}, 1-\mathrm{y}, 1-\mathrm{z}$

asymmetric unit respectively, whereas the compound $\mathbf{3}$ crystallizes in the monoclinic crystal system with one molecule in the asymmetric unit, compound $\mathbf{4}$ crystallizes in the orthorhombic crystal system along with a DMF solvent molecule. In all the compounds (1-5), the thiazolopyrimidine ring has almost similar substituent such as aryl, carboxylate and methyl groups at C5, C6 and C7 positions respectively. We have substituted nitrile, dimethyl-vinyl-amine and 3-cyanobenzylidene groups at $\mathrm{C} 2$ position in compounds 2,3 and 4 respectively. The position $\mathrm{C} 3$ has different substituents such as, phenyl, amine, oxo, oxo and ethyl carboxylate groups in compounds $\mathbf{1 - 5}$ respectively. The fused thiazole ring is essentially planar with a r.m.s deviation for compounds $\mathbf{1 - 5}$ being 0.0078 Á, 0.0093 Á, 0.0169 Á, $0.0167 \AA$ Á and 0.0091 Á respectively. The central pyrimidine ring in compounds $2,3,4$ and 5 adopts a twist boat conformation due to the deviation of atoms $\mathrm{C} 5$ and $\mathrm{N} 2$ from the mean plane $\mathrm{C} 6 / \mathrm{C} 7 / \mathrm{C} 9 / \mathrm{N} 1$ constituting the ring by $-0.230(5) / 0.094(4), 0.367(1) /$ $-0.084(1), 0.253(5) /-0.105(4)$ and $0.55(4) / 0.033(3) \AA$, respectively. ${ }^{9 b, 19}$ The ring puckering parameters ${ }^{20}$ for the pyrimidine ring of compound $\mathbf{2}$ are $\mathrm{Q}(\mathrm{T})=$ $0.2113(4) / 0.177(4) \hat{A}, \varphi(2)^{\circ}=-18.53(1) /-5.32(2)$ and $\theta(2)^{\circ}=118.48(1) / 125.07(2)$ the two values 
Table 3. Conformational parameters of thiazolopyrimidines.

\begin{tabular}{|c|c|c|c|c|c|c|c|}
\hline \multirow{2}{*}{$\begin{array}{l}\text { Compound } \\
\text { code }\end{array}$} & \multicolumn{4}{|c|}{ Different substituent at } & \multirow{2}{*}{$\begin{array}{l}\text { Orientation of the aryl } \\
\text { group w.r.t. C5-H5 / } \\
\text { Plane of thiazolopy- } \\
\text { rimidine }\end{array}$} & \multirow{2}{*}{$\begin{array}{l}\text { Deviating atoms } \\
\text { from the mean } \\
\text { plane of thiazo- } \\
\text { lopyrimidine }\end{array}$} & \multirow{2}{*}{$\begin{array}{l}\text { Dihedral angle } \\
\text { between the aryl } \\
\text { and pyrimidine/ } \\
\text { thiazolopyri- } \\
\text { midine ring }\end{array}$} \\
\hline & $\overline{\mathrm{C} 2}$ & C3 & $\mathrm{C} 5$ & C6 & & & \\
\hline 1 & $\mathrm{H}$ & $\mathrm{Ph}$ & $\mathrm{Ph}$ & $\mathrm{CO}_{2} \mathrm{Et}$ & Synperipl-anar /both & Only C5 & 82.80 \\
\hline 2 & $\mathrm{CN}$ & $\mathrm{NH}_{2}$ & $\mathrm{Ph}$ & $\mathrm{CO}_{2} \mathrm{Me}$ & $\begin{array}{l}\text { Antiperipl-anar / } \\
\text { Aryl down }\end{array}$ & $\mathrm{C} 5$ and $\mathrm{N} 2$ & 88.12 \\
\hline 3 & $=\mathrm{CHNMe}_{2}$ & $=\mathrm{O}$ & $\mathrm{Ph}$ & $\mathrm{CO}_{2} \mathrm{Et}$ & $\begin{array}{l}\text { Antiperipl-anar / } \\
\text { Aryl down }\end{array}$ & $\mathrm{C} 5$ and $\mathrm{N} 2$ & 84.00 \\
\hline 4 & $\begin{array}{l}\text { 3-Cyano } \\
\text { benzylidene }\end{array}$ & $=\mathrm{O}$ & 4-OH-Ph & $\mathrm{CO}_{2} \mathrm{Me}$ & $\begin{array}{l}\text { Synperipl-anar / } \\
\text { Aryl up }\end{array}$ & $\mathrm{C} 5$ and $\mathrm{N} 2$ & 87.56 \\
\hline 5 & $\mathrm{H}$ & $\mathrm{CH}_{2} \mathrm{CO}_{2} \mathrm{Et}$ & $\begin{array}{l}\text { 4-OH, } \\
3-\mathrm{OCH}_{3}-\mathrm{Ph}\end{array}$ & $\mathrm{CO}_{2} \mathrm{Me}$ & $\begin{array}{l}\text { Synperipl-anar / } \\
\text { Aryl up }\end{array}$ & $\mathrm{C} 5$ and $\mathrm{N} 2$ & 81.00 \\
\hline
\end{tabular}

separated by ' $\%$ correspond to the two molecules 2 a and $\mathbf{2} \mathbf{b}$ in the asymmetric unit. The ring puckering parameters for the pyrimidine ring of compound $\mathbf{3}$ are

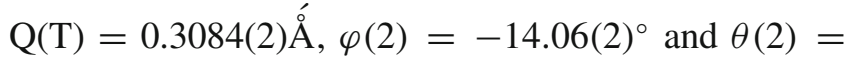
$69.33(1)^{\circ}$, the ring puckering parameters for the pyrimidine ring of compound $\mathbf{4}$ are $\mathrm{Q}(\mathrm{T})=0.2369(5) \AA$, $\varphi(2)=160.75(1)^{\circ}$ and $\theta(2)=112.44(1)^{\circ}$ and for compound 5 are $\mathrm{Q}(\mathrm{T})=0.0578$ (4) $\AA^{\circ}, \varphi(2)=$ $155.69(4)^{\circ}$ and $\theta(2)=112.96(1)^{\circ}$. In compounds 2 5 , we have observed deviation of $\mathrm{C} 5$ and $\mathrm{N} 2$ from the mean plane, which is a common feature observed in all thiazolopyrimidine structures. However, we have observed an unusual feature in the case of compound 1 where only C5 chiral carbon atom is significantly puckered and adopts half chair conformation with $\mathrm{C} 5$ atom being deviated by 0.149 (4) Å. The ring puckering parameters for the pyrimidine ring of compound $\mathbf{1}$ are $\mathrm{Q}(\mathrm{T})=0.2737(3) / 0.2815(3) / 0.1977(4) / 0.208(4) \AA$, $\varphi(2)^{\circ}=-7.99(8) / 172.41(8) /-15.87(2) / 163.49(1)$ and $\theta(2)^{\circ}=114.69(7) / 68.75(7) / 118.39(1) / 64.13(1)$ the four values separated by ' $/$ correspond to the four molecules $\mathbf{1}(\mathbf{a}-\mathbf{d})$ in the asymmetric unit.

In compounds $\mathbf{3}, \mathbf{4}$ and $\mathbf{5}$, the aryl ring is positioned in such a way that there are C-H. . . $\pi$ (arene) intramolecular interactions. However, in compounds $\mathbf{1}$ and $\mathbf{2}$ the aryl ring almost bisects the pyrimidine ring. The orientation of the phenyl group at $\mathrm{C} 5$ is evidenced from the absence of intramolecular C-H... $\pi$ interaction. The carboxylate group at $\mathrm{C} 6$ adopts $c i s$ conformation with respect to $\mathrm{C} 6=\mathrm{C} 7$ bond in compounds $\mathbf{1}, \mathbf{2}, \mathbf{3}$ and 5 because of intramolecular hydrogen bond between carbonyl group of ester and methyl substituent at C7, whereas in compound $\mathbf{4}$ it adopts trans conformation. In compound $\mathbf{5}$, the ethyl carboxylate group at $\mathrm{C} 17$ is almost parallel to the aryl ring with dihedral angle of $12.16^{\circ}$ due to intramolecular carbonyl... interaction ${ }^{21}$ between the ethyl carboxylate and aryl ring, a similar feature was observed in another derivative reported earlier. ${ }^{9 b}$

The intermolecular interaction of compound $\mathbf{1}$ is quite complicated since there are four molecules in the asymmetric unit. The four molecules of compound $\mathbf{1}$ are linked through $\mathrm{C} 2 \mathrm{~d}-\mathrm{H} 2 \mathrm{~d}$. . .O2d and C22d-H22d. . O 2d interactions resulting in the sheet like structure running along crystallographic 'a' axis (figure 2). The molecules 1c \& 1d which are interconnected through C12c-H12c...N2d, and C12d-H12d...N2c forms centrosymmetric head to head dimers with graph set $^{22}$ motif $R_{2}^{2}(14)$ along ' $c$ ' axis, in one case $N 2 d$ is the acceptor and in the other case it is N2c. In addition, C18d-H18d. . O $2 \mathrm{c}$ interaction links with the above two interactions to form centrosymmetric head to head dimers with graph set motif $\mathrm{R}_{2}^{2}(18)$. The above three interactions of the molecules $\mathbf{1 c} \& \mathbf{1 d}$ leads to a parallel arrangement of molecules in a zigzag manner along 'b' axis (figure 3). The other two molecules 1a \& $\mathbf{1 b}$ within the unit cell are arranged in syndiotactic manner along 'b' axis without any strong intermolecular interaction. In addition to these interactions, the molecules 1c \& 1d are linked into dimers by two C-H. . .Cg interactions (table 2); atoms $\mathrm{C} 8 \mathrm{c}$ and $\mathrm{C} 8 \mathrm{~d}$ in the molecule act as donor, via $\mathrm{H} 8 \mathrm{c} 2$ and $\mathrm{H} 8 \mathrm{~d} 2$ atoms respectively, to the thiazolopyrimidine ring. The additional C13a$\mathrm{H} 13 \mathrm{a} . . . \mathrm{Cg}$ (centroid of the $\mathrm{C} 11 \mathrm{c}-\mathrm{C} 16 \mathrm{c}$ ring) interaction is also observed between molecules 1 a $\&$ 1c.

The crystal structure of compound $\mathbf{2}$ is stabilized by intermolecular N-H. ..N and C-H. . .O interactions. There are three types of $\mathrm{N}-\mathrm{H} . . \mathrm{N}$ interactions, in which two interactions N3a-H3a1...N2b, and N3b-H3b2. . N4a result in sheet like structure. These sheets are further connected through N3b-H3b...N2b interactions. The C13a-H13a. . .O1b interaction bridges 


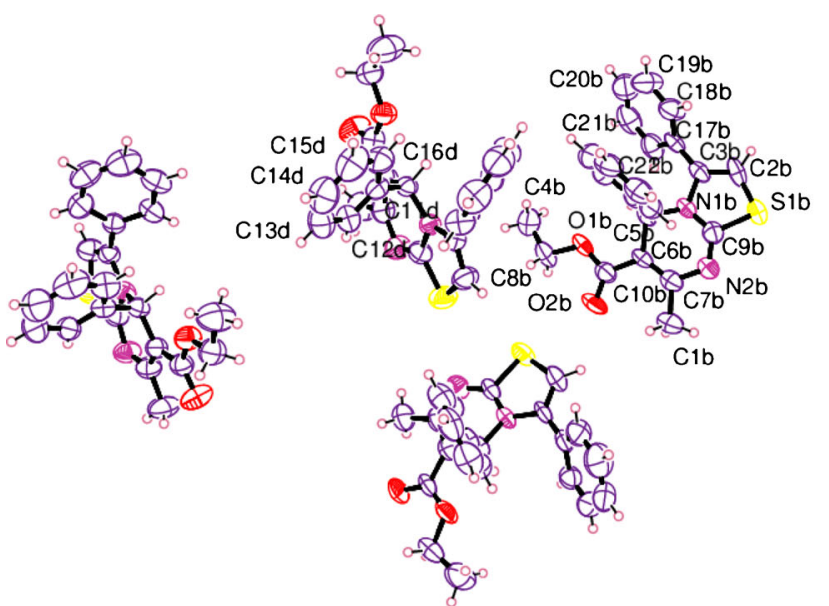

1(a-d)

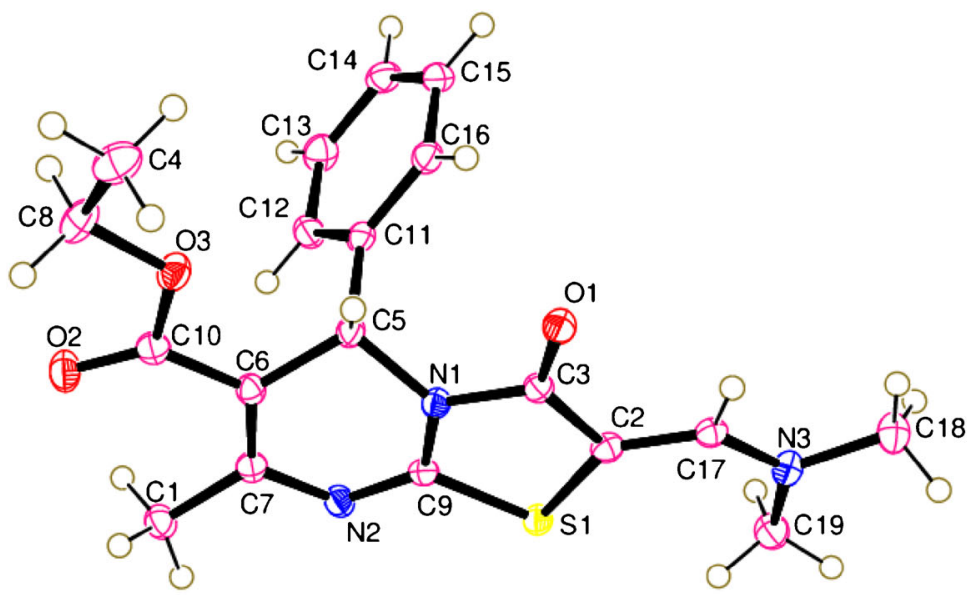

3

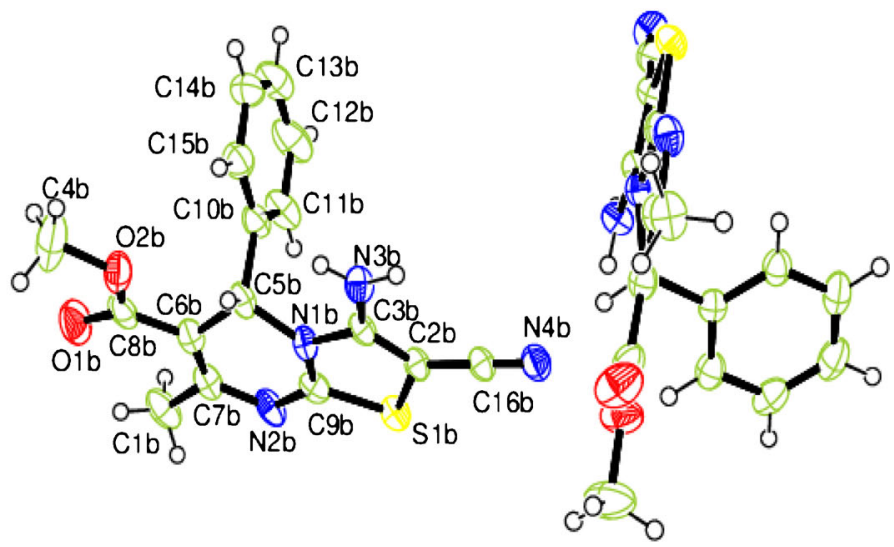

$2 a \& 2 b$

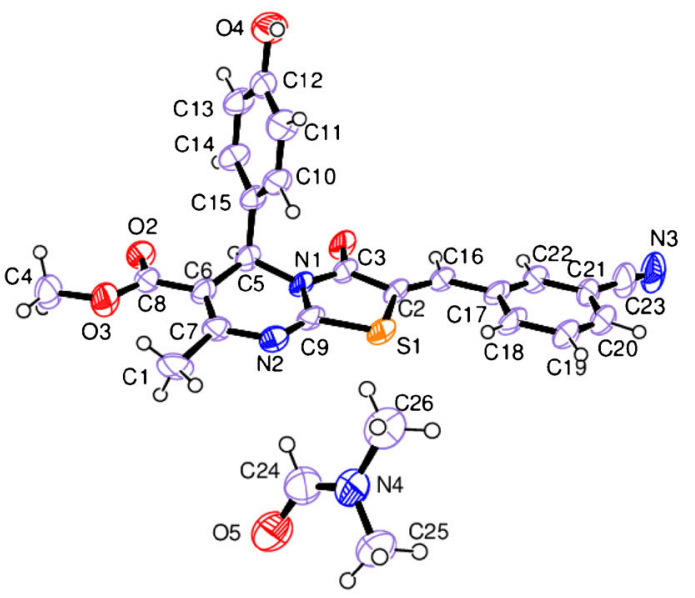

4

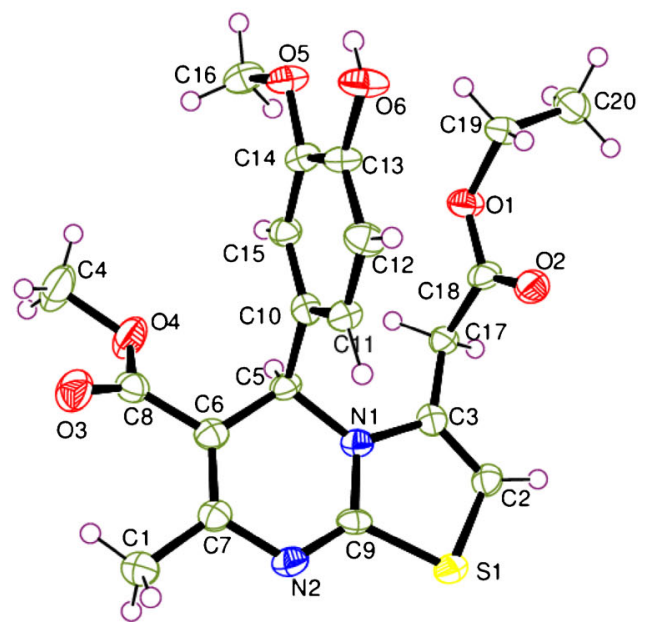

5

Figure 1. ORTEP view of compounds 1-5 with four, two, one, one and one molecule in the asymmetric unit respectively, showing $50 \%$ probability ellipsoids and the atom numbering scheme. 


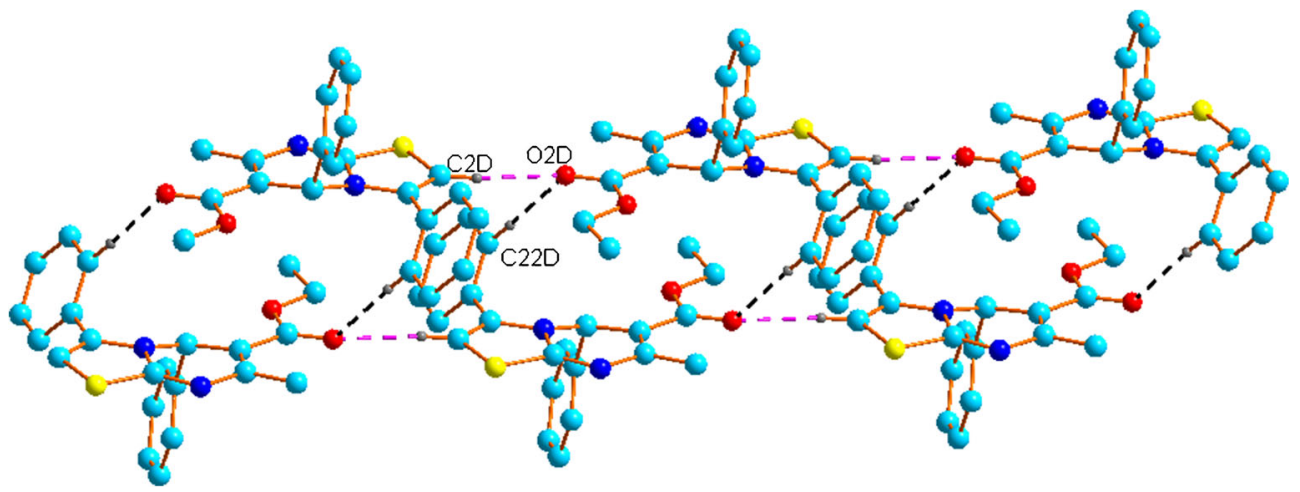

Figure 2. Packing of the molecules of compound 1 showing C-H...O intermolecular interactions along 'a' axis.

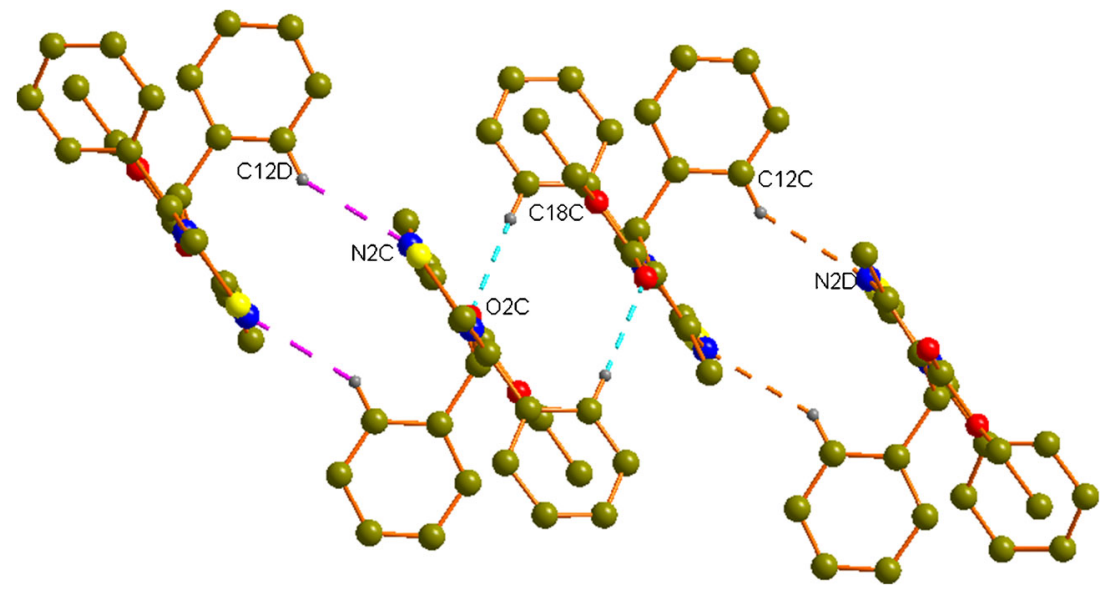

Figure 3. Formation of molecular dimers by $\mathrm{C}-\mathrm{H} . . . \mathrm{O}$ and $\mathrm{C}-\mathrm{H} . \ldots \mathrm{N}$ intermolecular interactions along ' $b$ ' axis in compound $\mathbf{1}$.

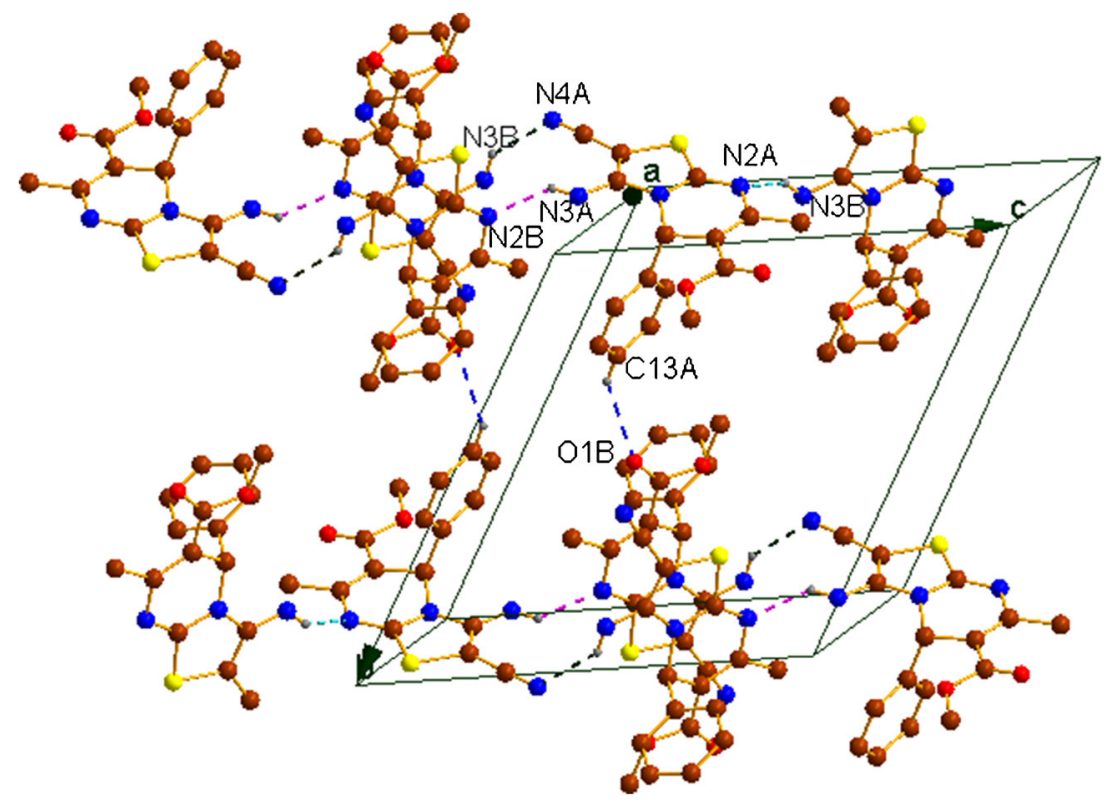

Figure 4. Packing diagram of compound 2 showing, C-H. . .O and N-H. . .N hydrogen bonds. 
the above set of interaction. The molecular packing of compound $\mathbf{2}$ is further stabilized by $\pi \ldots \pi$ stacking interactions between the thiazolopyrimidine

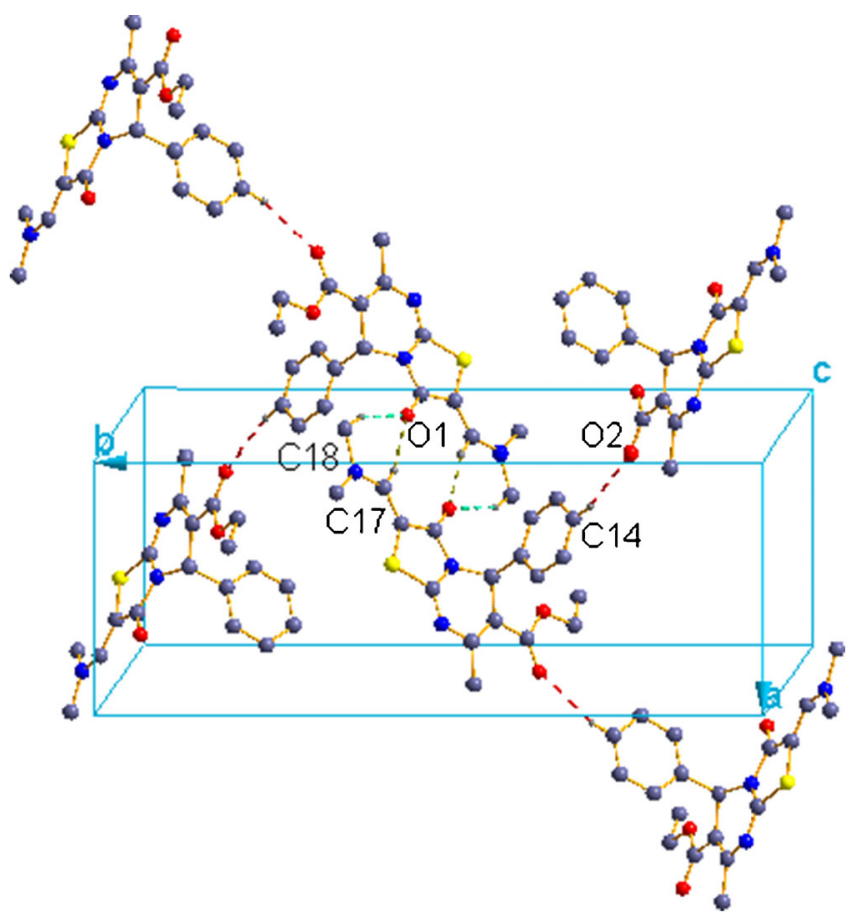

Figure 5. Dimers formed by C-H. .. contacts in compound $\mathbf{3}$. rings with the interplanar distances between the two rings being $3.447 \AA$. In comparison to compounds 1 and 2, compound $\mathbf{3}$ has no $\mathrm{C}-\mathrm{H} . . \mathrm{N}$ and $\mathrm{N}-\mathrm{H}$. . .N interaction. In compound $\mathbf{3}$ the molecular arrangement is consolidated by $\mathrm{C}-\mathrm{H}$. . .O type intermolecular interactions, involving carbonyl $\mathrm{O} 1$ forming centrosymmetric dimers with graph set notation $\mathrm{R}_{2}^{2}(10)$ and $\mathrm{R}_{1}^{2}(6)$ along ' $\mathrm{a}$ ' axis. The other $\mathrm{C} 14-\mathrm{H} 14$...O2 interaction connects the molecules into two dimensional network.

In compound 4 , the molecules are linked by two types of C-H. . .N interactions, i.e., C20-H20 . .N2 and C13-H13...N3. In the former interaction $\mathrm{C} 20(0.5+\mathrm{x}$, $2-\mathrm{y}, \mathrm{z})$ acts as a hydrogen donor to the N2 (1.5-x, y, $-0.5+\mathrm{z})$ atom of pyrimidine generating two dimensional sheets along ' $a$ ' axis, whereas in the later interaction $\mathrm{C} 13(0.5-\mathrm{x}, \mathrm{y}, 0.5+\mathrm{z})$ acts as a donor to $\mathrm{N} 3(0.5+\mathrm{x}$, $2-y, 1+z)$ of the nitrile group generating helical pattern running along 'c' axis. As in compound 1, it exhibits two types of $\mathrm{C}-\mathrm{H}$...O interactions, the former generates bifurcated bonds from two donors, C16 and C14, to the same acceptor $\mathrm{O} 2$ along ' $\mathrm{a}$ ' axis and the latter $\mathrm{C} 4-\mathrm{H} 4$... O5 forms the zig-zag chain running along 'c' axis. C-H. . Cg ( $\mathrm{Cg}$ is the centroid of phenyl ring $\mathrm{C} 11 / \mathrm{C} 12 / \mathrm{C} 13 / \mathrm{C} 14 / \mathrm{C} 15 / \mathrm{C} 16)$ at a distance of $3.020 \AA$ is also observed (table 2). In compound $\mathbf{5}, \mathrm{C}-\mathrm{H} . . \mathrm{N}$ interaction is absent; instead molecules are linked into

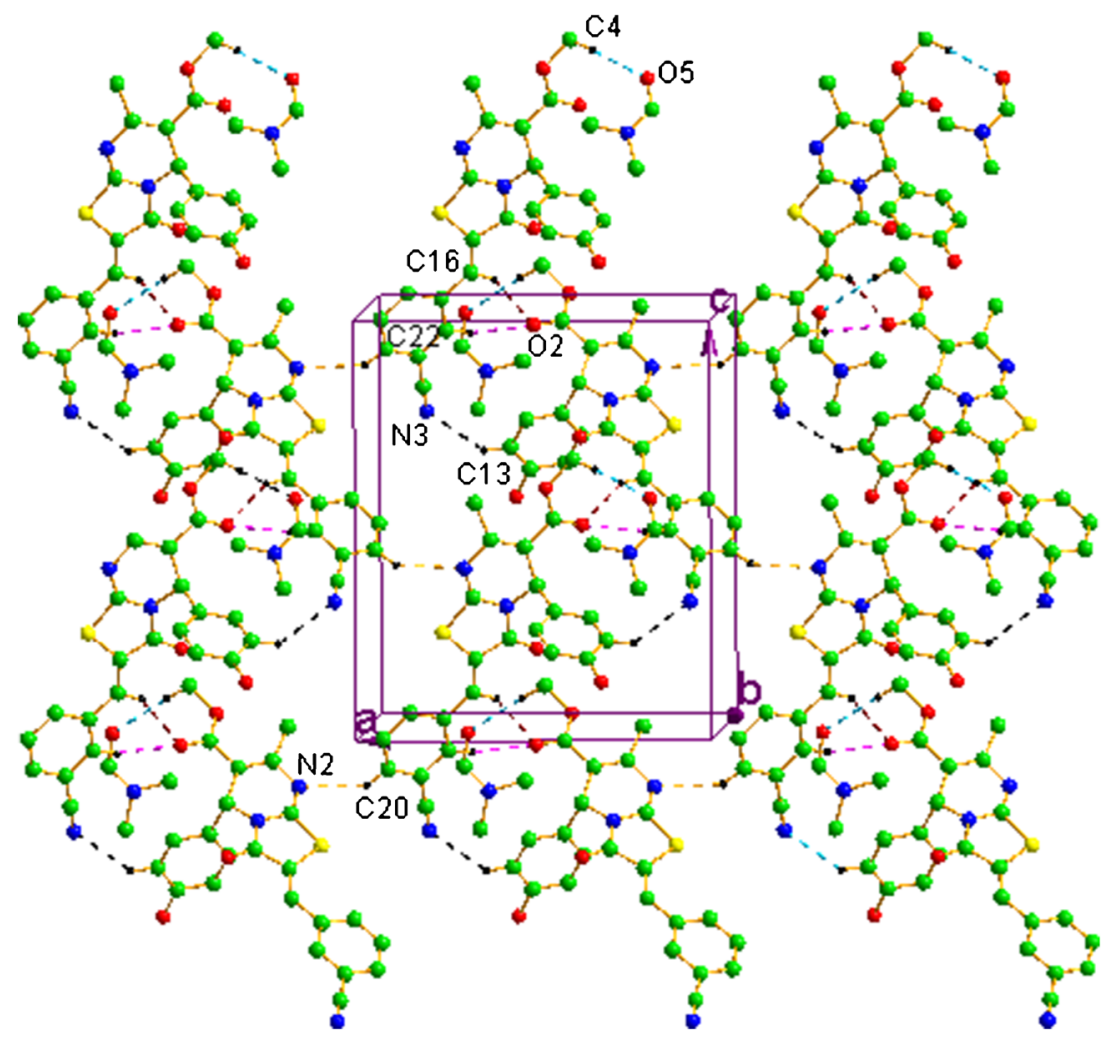

Figure 6. Crystal packing of compound 4 held by a network of C-H. . O and $\mathrm{C}-\mathrm{H}$. . .N interactions forming a three dimensional helical pattern. 


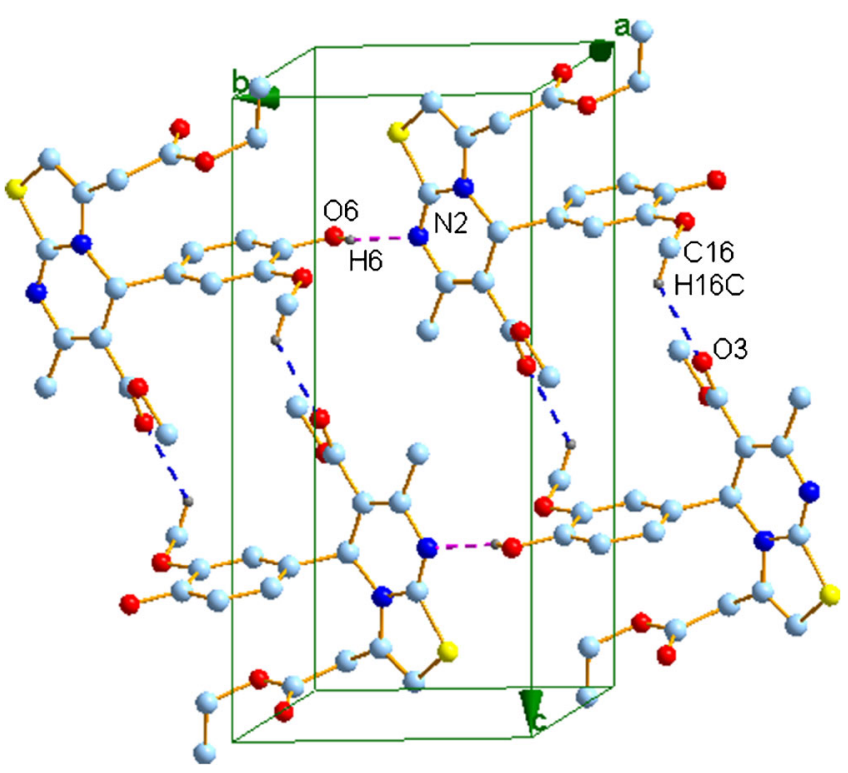

Figure 7. Packing of molecules via $\mathrm{C}-\mathrm{H}$. . . O and O-H. . N interactions in compound $\mathbf{5}$.

one dimensional chain through O6-H6. . N2 interaction along ' $b$ ' axis. The $\mathrm{C} 16-\mathrm{H} 16 . . \mathrm{O} 3$ interaction, wherein, the $\mathrm{C}-\mathrm{H}$ of the methoxy on aryl ring and carboxylate $\mathrm{O}$ at $\mathrm{C} 3$ of the thiazolopyrimidine forms centrosymmetric head to head dimers with graph set motif $\mathrm{R}_{2}^{2}(20)$ along ' $c$ ' axis resulting in the same pattern as that observed for compound 4. As in compounds 1 and 4, the packing in compound $\mathbf{5}$ is further stabilized by $\mathrm{C}-\mathrm{H} . . \mathrm{Cg}$ interaction between the aryl hydrogen and thiazole ring (table 2).

The five compounds discussed in this work possess most structural aspects, if not all, of the classical dihydropyrimidines which predispose them to excellent receptor-binding prospects. From the above conformational features it can be inferred that all of them have exploitable potential to function as calcium channel blockers. ${ }^{23-25}$

\section{Conclusion}

In this work, we have analyzed different thiazolopyrimidine derivatives by varying the substituents on the thiazolopyrimidine ring. With respect to weak interactions, it can be inferred that by changing the substituents at $\mathrm{C} 2, \mathrm{C} 3, \mathrm{C} 6$ and the substituent on the aryl ring at $\mathrm{C} 5$ of the thiazolopyrimidine, there is substantial alteration in the mode of intermolecular interactions. With regard to their supramolecular assemblies, all of them show a remarkable propensity to form dimers, often centrosymmetric and head-to-head ones involving C-H. . .O bonds. Apart from this, their crystal structures are rendered cohesive by intermolecular C-H...N, O-H...N and N-H...N hydrogen bonds. Apart from the above, there is novel coexistence of intramolecular carbonyl..$\pi$ in compound 5. In addition, C-H. . $\pi$ and $\pi \ldots \pi$ interactions are also observed.

\section{Supplementary Information}

The CIF files are deposited at the Cambridge Crystallographic Data Centre, The deposition numbers for compounds 1-5 are CCDC-917410, CCDC-942734, CCDC-942735, CCDC-997509 and CCDC-917409 respectively. These data can be obtained free of charge at www.ccdc.cam.ac.ul/conts/retrieving.html [or from the Cambridge Crystallographic Data Centre (CCDC), 12 Union Road, Cambridge CB2 1EZ, UK; fax: +44(0)1223-336033; email: deposit@ccdc.cam.ac.uk].

\section{Acknowledgement}

N S B acknowledges the financial support by University Grants Commission (UGC), New Delhi, under the major research project [F-No-37-86/2009(SR)]. H N thanks UGC for the fellowship.

\section{References}

1. El-Emary T I and Abdel-Mohsen S A 2006 Phosphorus, Sulfur Silicon Relat. Elem. 1812459

2. Mohamed S K Y, Ragaa A A, Mohamed S A, Shawkat A A and Ahmed A O 2008 Monatsh Chem. 139553

3. Nagarajaiah H, Khazi I M and Begum N S 2012 J. Chem. Sci. 124847

4. Sayed H H, Morsy E M H and Kotb E R 2010 Syn. Com. 402712

5. Yaragatti N B, Kulkarni M V, Ghate M D, Hebbar S S and Hegde G R 2010 J. Sulfur Chem. 31123

6. Abu-Hashem A A, Gouda M A and Badria F A 2010 Eur. J. Med. Chem. 451976

7. Hui Z, Lan-mei C, Lin-lin Z, Si-jie L, David C C W, Huang-quan L and Chun H 2008 ARKIVOC. 8266

8. Ozair A, Suroor A K, Nadeem S and Waquar A 2010 Med. Chem. Res. 191245

9. a) Nagarajaiah H, Fathima N and Begum N S 2012 Acta Cryst. E 68 o1257; b) Nagarajaiah H and Begum N S 2012 Acta Cryst. E 68 o2878; c) Nagarajaiah H and Begum N S 2011 Acta Crystallogr. E 67 o3444

10. Mobinikhaledi A and Foroughifar N 2004 Phosphorus, Sulfur Silicon Relat. Elem. 1791175

11. Singh S, Schober A, Gebinoga M and Alexander G G 2011 Tetrahedron. 523814

12. Bruker, SMART, SAINT-Plus, SADABS. Bruker Axs Inc. 1998 Madison, Wisconcin, USA 
13. Sheldrick G M 2008 Acta Cryst. A 64112

14. Nardelli M 1983 Acta Cryst. C 391141

15. Farrugia L J 1997 J. Appl. Cryst. 30565

16. Spek A L 2009 Acta Cryst. D 65148

17. Watkin D J, Prout C K and Pearce L J 1996 CAMERON. Chemical Crystallography Laboratory, University of Oxford, England

18. Brandenburg K and Putz H 2005 Crystal Impact. GbR, Bonn, Germany

19. Mukesh M J, Bharat B B and Jerry P J 2010 Acta Cryst. E 660599
20. Cremer D and Pople J A 1975 J. Am. Chem. Soc. 971354

21. Gautrot J E, Hodge P, Cupertino D and Helliwell M 2006 New J. Chem. 301801

22. Bernstein J, Davis R E, Shimoni L and Chang N L 1995 Angew. Chem. Int. Ed. Engl. 341555

23. Kappe C O 1998 Molecules 31

24. Rovnyak G C, Kimball S D, Beyer B, Cucinotta G, DiMarco J D, Gougoutas J Z, Hedberg A, Malley M, McCarthy J P, Zhang R and Moreland S 1995 J. Med. Chem. 38119

25. Kappe C O 2000 Eur. J. Med. Chem. 351043 